\title{
COMPOSTOS BIOATIVOS EM FLORES COMESTÍVEIS
}

\author{
Joelma Gonçalves ${ }^{1}$, Gabriela Conceição Oliveira Silva' ${ }^{1}$ Lanamar Almeida Carlos ${ }^{2 *}$
}

\section{RESUMO}

GONÇALVES, J.; SILVA, G.C.O. \& CARLOS, L.A. Compostos bioativos em flores comestíveis. Perspectivas Online: Biológicas \& Saúde. v. 9, n 29, p.11-20, 2019.

O uso de flores comestíveis ganha destaque, dentre os alimentos funcionais, devido à presença de compostos bioativos, que são capazes de neutralizar os radicais livres e contribuir para uma alimentação saudável e equilibrada. $\mathrm{O}$ objetivo do estudo foi avaliar o perfil de compostos bioativos em flores comestíveis de cinco espécies de plantas, sendo quatro consideradas não convencionais. Avaliou-se os teores de carotenoides, compostos fenólicos, flavonoides e antocianinas em couve-flor roxa e couve-flor verde (convencionais), e flores de ipêamarelo, amor-perfeito, capuchinha (vermelha e laranja) e ora-pro-nobis, consideradas plantas alimentícias não convencionais (PANC). As variáveis foram submetidas a análise de variância, em delineamento inteiramente casualizado, com três repetições, seguido do teste de Tukey, ao nível de 5\% de significância. As flores de ipê-amarelo apresentaram maiores conteúdos de carotenoides totais $\left(1.443,3 \mu \mathrm{g} .100 \mathrm{~g}^{-1}\right)$. As flores de amor-perfeito e capuchinha-laranja apresentaram os maiores teores de compostos fenólicos (2,9 e 3,2 g EAG.100 $\left.\mathrm{g}^{-1}\right)$, de flavonoides $\left(294,2\right.$ e $\left.106,4 \mathrm{mg} .100 \mathrm{~g}^{-1}\right)$ e de antocianinas $\left(45,1\right.$ e $\left.58,9 \mathrm{mg} \cdot 100 \mathrm{~g}^{-1}\right)$. Foram detectadas as presenças de compostos bioativos dos grupos dos carotenoides, dos flavonoides e das antocianinas e em todas as flores comestíveis avaliadas. As flores de orapro-nobis e de couve flor verde, foram as que apresentaram os menores conteúdos dos compostos bioativos.

Palavras-chave: Fitoquímicos; Compostos fenólicos; antioxidantes naturais. 


\begin{abstract}
The use of edible flowers gains prominence, among functional foods, due to the presence of bioactive compounds, which are able to neutralize free radicals and contribute to a healthy and balanced diet. The objective of this study was to evaluate the profile of bioactive compounds in edible flowers of five plant species, four of which were considered unconventional. Carotenoids, phenolic compounds, flavonoids and anthocyanins were evaluated in purple cauliflower and green cauliflower (conventional), and flowers of yellow ipê, pansy, nasturtium (red and orange) and Barbados gooseberry, considered unconventional food plants (UFP). The variables were submitted to analysis of

with three replications, followed by the Tukey test, at the 5\% level of significance. The flowers of yellow ipê have presented higher contents of total carotenoids $(1,443.3 \mu \mathrm{g} .100$ $\left.\mathrm{g}^{-1}\right)$. The pansy and orange-nasturtium flowers presented the highest levels of phenolic compounds (2.9 and $3.2 \mathrm{~g}^{\mathrm{E}}$ EAG.100 $\mathrm{g}^{-1}$ ), flavonoids (294.2 and $106.4 \mathrm{mg} .100 \mathrm{~g}^{-1}$ ) and anthocyanins (45.1 and $58.9 \mathrm{mg} .100 \mathrm{~g}^{-1}$ ). The presence of the bioactive compounds such as carotenoid, flavonoid and anthocyanin groups was detected in all edible flowers evaluated. The flowers of Barbados gooseberry and green cauliflower were the ones that presented the lowest contents of the bioactive compounds.
\end{abstract} variance, in a completely randomized design,

Keywords: Phytochemicals; Phenolic componds; Natural antioxidants.

\footnotetext{
${ }^{1}$ Universidade Federal de São João del-Rei - UFSJ - Pós graduandos em Ciências Agrárias - Rod. MG-424, km 47 Sete Lagoas - MG, CEP: 35.701-970 - Brasil.

2 Departamento de Engenharia de Alimentos - DEALI - UFSJ/MG

(*) e-mail: lanamar@ufsj.edu.br

Data de recebimento: 22/03/2019 Aceito para publicação: 09/05/2019
}

Persp. online: biol. \& saúde, Campos dos Goytacazes, 29 (9), 11-20, 2019 


\section{INTRODUÇÃO}

Uma alimentação saudável e equilibrada é constituída de um consumo diário de nutrientes, vitaminas, carboidratos, proteínas e fibras (BRASIL, 2014; OMS, 2015). Segundo Silva et al. (2016), o consumo de vegetais in natura contribui para uma alimentação saudável em razão de algumas vantagens, como o fornecimento de considerável percentual de vitaminas, sais minerais e fibras alimentares, além de compostos com atividade antioxidante.

Os chamados alimentos funcionais apresentam não só valor nutritivo, mas também propriedades que trazem benefícios fisiológicos ao organismo (COSTA e ROSA, 2010). Tal capacidade de promover bem estar e melhorias no estado de saúde deve-se em parte à presença dos compostos bioativos, também chamados fitoquímicos. Esses compostos apresentam grande importância para o organismo, pelo fato de atuarem na neutralização do excesso de radicais livres produzidos pelo estresse oxidativo. Assim, a ingestão de alimentos ricos em compostos naturais com atividade antioxidante promovem a redução do risco de doenças crônicas não transmissíveis (DCNT), como câncer, diabetes, obesidade, osteoporose e algumas doenças cardiovasculares (LLORACH et al., 2008; CHITARRA e CHITARRA, 2005).

Os compostos bioativos, que estão presentes em todas as partes dos vegetais, são em sua maioria, produtos do metabolismo secundário das plantas, e apresentam funções de atração de polinizadores e disseminadores de sementes além de exercerem importante função na proteção contra estresses bióticos e abióticos (BORELLA et al., 2012).

Dentre as diversas classes de compostos bioativos, os compostos fenólicos possuem grande importância funcional, compreendem dois grandes grupos: os flavonoides e os não flavonoides. Os flavonoides, por sua vez, compreendem outros seis grupos de compostos, entre eles, as antocianinas (BOROSKI et al., 2015). Estas são os principais compostos responsáveis pela vasta tonalidade de cores encontradas nas flores, como vermelho, alaranjado, roxo, rosa e azul. Outra classe presente é a dos tetraterpenos, que inclui o grupo dos carotenoides, importantes antioxidantes naturais. Os carotenoides são pigmentos acessórios, com coloração variando do amarelo ao laranja ou vermelho, e tem como principal função a proteção contra foto-oxidação (TAIZ e ZEIGER, 2013).

As flores comestíveis trazem melhorias à qualidade sensorial e nutricional da alimentação, uma vez que diversas espécies de flores comestíveis possuem altos teores de compostos bioativos com propriedades nutracêuticas (FERNANDES et al., 2017; LOIZZO et al., 2016; PIRES et al., 2018). Seu uso ganha destaque nas preparações culinárias, especialmente na culinária goumert, proporcionando não só beleza, mas também, aroma, cor e sabor aos pratos preparados (KINUPP e LORENZI, 2014).

Os compostos bioativos em flores apresentam teores bastante variáveis em função de cada espécie. Os flavonoides mais encontrados em flores comestíveis são a quercetina, kaempferol, miricetina, rutina, apigenina, luteolina, catequina e epicatequina. As antocianinas mais relatadas são cianidina, delfinidina e pelargonidina glicosiladas (FERNANDES et al., 2016).

Algumas flores já fazem parte da alimentação trivial da população, como a couve-flor,que é rica em sais minerais e vitaminas (MAY et al., 2007). Outras, consideradas plantas alimentícias não convecionais (PANC), estão presentes em pratos mais sofisticados, como a capuchinha, com propriedades anti-adipogênicas (KIM et al., 2017) e o amor-perfeito, capaz de prevenir doenças neurodegenerativas (MOUSAVI et al., 2016). Já as flores de ora-pro-nobis e ipê-amarelo, também

Persp. online: biol. \& saúde, Campos dos Goytacazes, 29 (9), 11-20, 2019

seer.perspectivasonline.com.br 
consideradas PANC, são usadas apenas por populações tradicionais, e estas demandam estudos fitoquímicos.

No sentido de ampliar o conhecimento sobre os compostos fitoquímicos presentes em flores comestíveis, o presente trabalho teve como objetivo avaliar o perfil de compostos bioativos, tais como carotenoides, compostos fenólicos, flavonoides e antocianinas, em flores comestíveis de cinco espécies de plantas, convencionais e não convencionais.

\section{METODOLOGIA}

Foram utilizadas 2 variedades de couve-flor: couve-flor roxa (Brassica oleraceae var. botrytis) e couve-flor verde (Brassica oleraceae var. italica), adquiridas na Ceasa-MG/Contagem, consideradas plantas alimentícias convencionais. As flores de ipê-amarelo (Tabebuia serratifolia), amor-perfeito Rosalyn (Viola $\times$ wittrockiana), capuchinha, sendo 2 variedades: capuchinhavermelha e capuchinha-laranja (Tropaeolum majus; Sinonímias: Tropaeolum pinnatum, Tropaeolum quinquelobum) e ora-pro-nobis (Pereskia grandifolia), consideradas plantas alimentícias não convencionais (PANC), foram coletadas de três diferentes plantas, no início da primavera de 2017, na região de Sete Lagoas-MG (latitude $19^{\circ} 28^{\prime} 4^{\prime \prime}$ Sul e longitude $44^{\circ} 14^{\prime} 52^{\prime \prime}$ Oeste). Foram avaliadas 3 diferentes amostras de cada flor, configurando 3 repetições e todas análises foram feitas em triplicata.

As cinco espécies de flores (Figura 1), incluindo as duas variedades de couve-flor e de capuchinha (sete amostras no total) com as suas respectivas repetições, foram separadas das folhas e dos caules, e toda a parte floral foi individualmente homogeneizada com o auxílio de um processador. As amostras foram acondicionadas e tubos plásticos com tampa e congeladas em ultrafreezer COLDLAB, modelo CL $374-80 \mathrm{~V}$ a $-40^{\circ} \mathrm{C}$ até o momento das análises.

Para determinação do teor de carotenoides totais seguiu-se a metodologia proposta por Rodriguez-Amaya (2004), que envolve extração por partição, utilizando acetona p.a. e éter de petróleo como extratores. A leitura das absorbâncias foram realizadas em espectrofotômetro FEMTO $700 \mathrm{~S}$ a $450 \mathrm{~nm}$ e os resultados foram expressos em $\mu \mathrm{g}$ carotenoides totais/ $100 \mathrm{~g}$ amostra fresca.

O teor de compostos fenólicos totais foi quantificado por espectrofotometria, utilizando reagente Folin-Ciocalteau (SINGLETON et al., 1999). A extração dos compostos fenólicos das amostras foi realizada com etanol $70 \%$. Os resultados foram expressos em miligramas equivalentes de ácido gálico (EGA). $100 \mathrm{~g}^{-1}$ de flor em base fresca (NEVES et al., 2009).

Os conteúdos de flavonoides totais e de antocianinas totais foram determinados segundo a metodologia de Lees e Francis (1971). Cerca de 0,5 gramas das amostras foram adicionadas de solução extratora de etanol 95\% acidificada com ácido clorídrico 1,5 N (85:15) em quantidade suficiente para completar o volume de $25 \mathrm{~mL}$. Após repouso de 24 horas, ao abrigo de luz procedeu-se a filtração e efetuou-se a leitura da absorbância em espectrofotometro FEMTO 700S a 734nm. Para a análise de antocianinas totais, aplicou-se o mesmo procedimento, porém com a leitura da absorbância a 535nm. Para cálculo do conteúdo de flavonoides totais e de antocianinas totais, utilizou-se as equações (a) e (b) respectivamente, onde $\mathrm{A}=$ absorbância e FD = fator de diluição. 

Flavonoides (mg. $\left.100 \mathrm{~g}^{-1}\right)=\frac{\mathrm{A} \times \mathrm{FD}}{76,6}$
Equação (a)
Antocianinas $\left(\mathrm{mg} .100 \mathrm{~g}^{-1}\right)=\frac{\mathrm{Ax} \mathrm{FD}}{98,2}$
Equação (b)

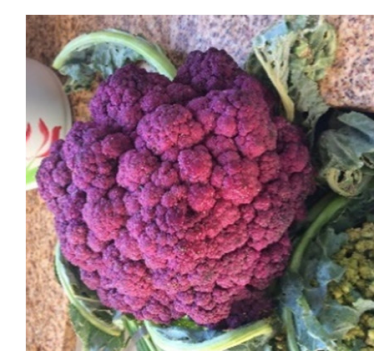

(a)

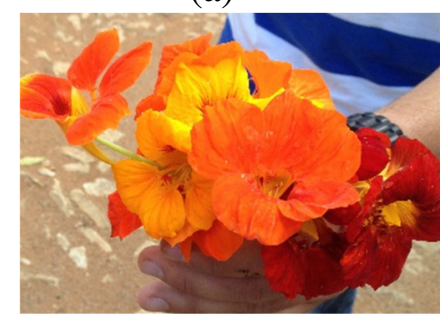

(d)

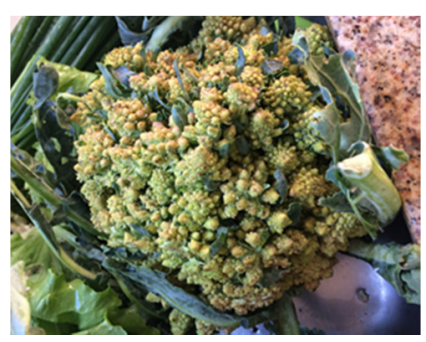

(b)

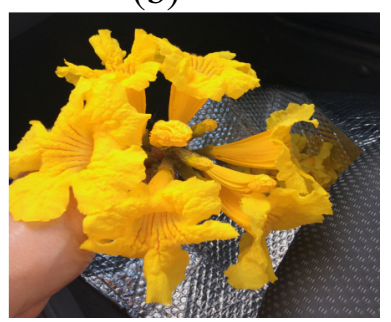

(e)

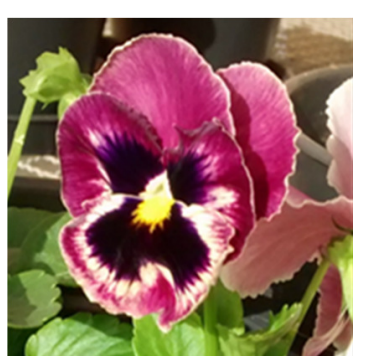

(c)

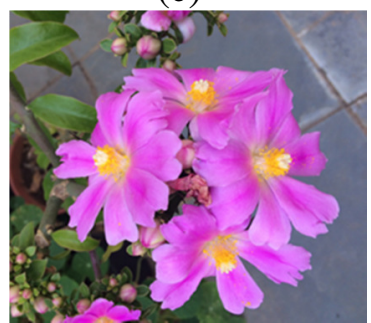

(f)

Figura 1. Flores de couve-flor roxa (a), couve-flor verde romanesca (b), amor-perfeito (c); capuchinha-vermelha e capuchinha-laranja (d), ipê amarelo (e) e ora-pro-nobis (f).

As variáveis foram submetidas a testes de homocedasticidade (Teste de Levene) e de normalidade (Teste de Lilliefors) ( $p>0,05)$. Alcançadas as pressuposições estatísticas, realizou-se análise de variância (ANOVA) ao nível de 5\% de significância, em delineamento inteiramente casualizados, com três repetições. As variáveis que apresentaram diferença significativa pelo teste $\mathrm{F}$ $(\mathrm{p}<0,05)$ tiveram suas médias comparadas pelo teste de Tukey ao nível de $5 \%$ de significância (pacote ExpDes.pt). Para tanto, utilizou-se o programa estatístico R, versão 3.4.3.

\section{RESULTADOS E DISCUSSÃO}

Houve diferença significativa no conteúdo de carotenoides totais entre as espécies de flores avaliadas $(\mathrm{p}<0,05)$, sendo que nas de ipê-amarelo foi detectado o maior teor desse analito, seguido das flores de capuchinha-laranja, com teores médios de 1.443,3 e 1.202,2 $\mu \mathrm{g}$ de carotenoides.100 g1 de amostra fresca, respectivamente. As flores de amor-perfeito e capuchinha-vermelha apresentaram teores médios de 708,5 e 616,2 $\mu \mathrm{g}$ de carotenoides.100 $\mathrm{g}^{-1}$ de amostra fresca, respectivamente. Já as flores de couve-flor verde, ora-pro-nobis e couve-flor roxa apresentaram os menores teores, com as respectivas médias de 152,5; 109,6 e 38,7 $\mu \mathrm{g}$ de carotenoides. $100 \mathrm{~g}^{-1}$ de amostra fresca, conforme apresentado na Figura 2-a.

O teor de compostos fenólicos totais apresentou diferença significativa entre as espécies de flores avaliadas $(\mathrm{p}<0,05)$ e o maior valor encontrado foi nas flores de capuchinha-laranja e de amorperfeito com médias de 3,2 e 2,9 g equivalente ácido gálico (EAG). $100 \mathrm{~g}^{-1}$ de amostra fresca, respectivamente. As flores de ipê-amarelo apresentaram teor médio de $1,25 \mathrm{~g}$ EAG $.100 \mathrm{~g}^{-1} \mathrm{de}$ amostra fresca e os menores teores foram encontrados nas flores de ora-pro-nobis, capuchinhavermelha, couve-flor roxa e couve-flor verde, com médias de 0,79; 0,77; 0,71 e 0,14 g EAG.100 g ${ }^{-1}$ de amostra fresca, respectivamente (Figura2-b).

Persp. online: biol. \& saúde, Campos dos Goytacazes, 29 (9), 11-20, 2019 
O teor de flavonoides totais apresentou diferença significativa entre as espécies de flores avaliadas $(\mathrm{p}<0,05)$, e as maiores concentrações foram detectadas nas flores de amor-perfeito, que apresentaram a média de 294,2 mg.100 g $\mathrm{g}^{-1}$ de amostra fresca. As flores de capuchinha-laranja, couve-flor roxa, ipê-amarelo, capuchinha-vermelha, ora-pro-nobis e couve-flor verde apresentaram teores médios de 106,$4 ; 74,6 ; 72,2 ; 64,7 ; 34,6$ e $33,5 \mathrm{mg} .100 \mathrm{~g}^{-1}$ de amostra fresca, respectivamente (Figura2-c).

O conteúdo de antocianinas totais foi significativamente diferente entre as espécies de flores avaliadas $(\mathrm{p}<0,05)$, sendo que os maiores teores foram detectados nas flores de capuchinha-laranja e de amor-perfeito (teores médios de 58,9 e 45,1 mg. $100 \mathrm{~g}^{-1}$ de amostra fresca, respectivamente). As flores de capuchinha-vermelha, couve-flor roxa, ipê-amarelo, couve-flor verde e ora-pro-nobis, apresentaram teores médios de 24,5; 17,4; 9,6;4,7 e 2,8 mg.100g ${ }^{-1}$ de amostra fresca, respectivamente (Figura2-d).
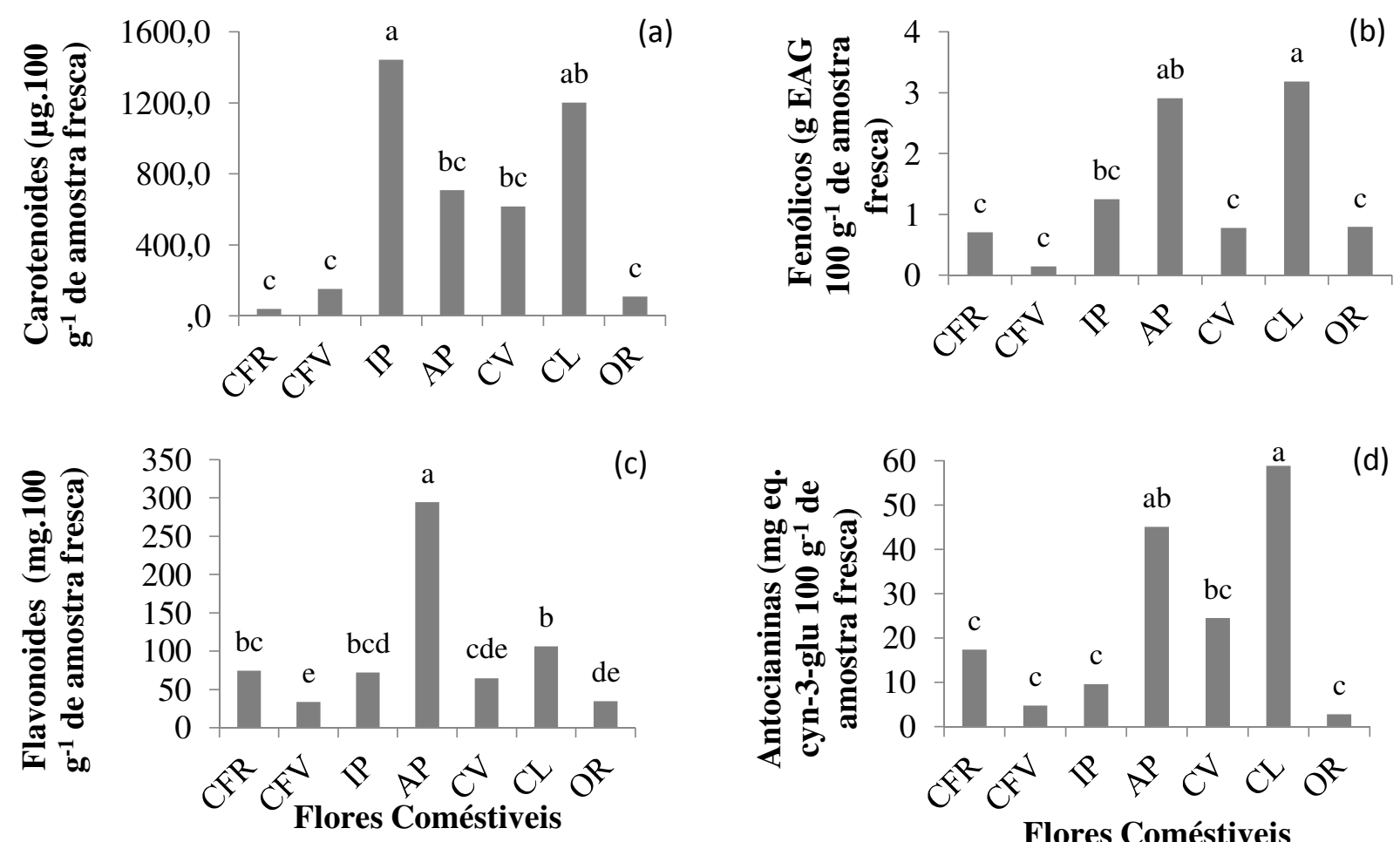

Flores Coméstiveis

Médias seguidas de pela mesma letra, não diferem entre si pelo teste de Tukey ao nível de 5\% de significância.

Figura 2. Teores de carotenoides totais (a), compostos fenólicos totais (b), flavonoides totais (c) e antocianinas totais (d) em flores comestíveis: couve-flor roxa (CFR), couve-flor verde (CFV), ipê amarelo (IP), amor-perfeito (AP), capuchinha-vermelha (CV), capuchinha-laranja (CL) e orapro-nobis (OR).

Os teores de carotenoides totais encontrados, neste estudo, para amor-perfeito, capuchinhavermelha e capuchinha-laranja $\left(708,5 ; 616,2\right.$ e $1.202,2 \mu \mathrm{g}$ de carotenoides. $100 \mathrm{~g}^{-1} \mathrm{de}$ amostra fresca, respectivamente) foram bem superiores aos relatados por Vieira (2013), cujas amostras apresentaram valores de 0,$15 ; 0,11$ e $0,03 \mu \mathrm{g}$ de carotenoides. $100 \mathrm{~g}^{-1}$ de amostra fresca de flor, para amor-perfeito, capuchinha-vermelha e capuchinha-laranja, respectivamente. $\mathrm{O}$ teor de carotenoides

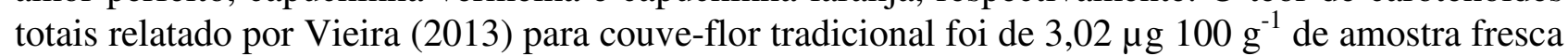
de flor, em nosso estudo, os valores encontrados para couve-flor verde e roxa foram de 152,6 e 38,8 $\mu \mathrm{g} 100 \mathrm{~g}^{-1}$ de amostra fresca de flor, respectivamente. 
Em estudos de Botrel et al. (2015), o teor de carotenoides totais encontrado nas flores frescas de capuchinha-laranja também foi bem inferior ao encontrado neste estudo, com média de $381,1 \mu \mathrm{g}$ de carotenoides. $100 \mathrm{~g}^{-1}$ de amostra fresca de flor. Teor inferior de carotenoides totais para flor de amor-perfeito também foi encontrado por Grzeszczuk et al. (2016), com valor de 426,0 $\mu \mathrm{g}$ de carotenoides. $100 \mathrm{~g}^{-1}$ de amostra fresca de flor.

Os mais altos teores de carotenoides foram detectados nas flores de ipê-amarelo e de capuchinha-laranja, que apresentam colorações mais intensas. Estes resultados corroboram as observações de Taiz e Zeiger (2013), que citaram que os carotenoides estão mais atuantes em flores de coloração que variam do amarelo ou laranja ao vermelho. Além disso, diferenças de teores entre gêneros, espécies e, até mesmo variedades, são passíveis de ocorrer (FERNANDES et al. 2016; ZHAO e TAO, 2015).

Os teores de compostos fenólicos totais, detectados neste estudo e expressos em g EAG.100 $\mathrm{g}^{-1}$ de amostra fresca, para flores de amor-perfeito $(2,9)$, capuchinha-laranja $(3,2)$, couve-flor roxa $(0,7)$, couve-flor verde $(0,15)$ e capuchinha-vermelha $(0,8)$ foram próximos aos relatados por VIEIRA (2013) para as flores de amor-perfeito (3,7 g EAG.100 $\mathrm{g}^{-1}$ de amostra fresca), superior ao encontrado nas flores de capuchinha-laranja (1,8 g EAG.100 $\mathrm{g}^{-1}$ de amostra fresca) e inferior ao encontrado nas flores couve-flor tradicional e capuchinha-vermelha $\left(1,2\right.$ e 2,6 g EAG $100 \mathrm{~g}^{-1} \mathrm{de}$ amostra fresca, respectivamente). Já, nos estudos de Grzeszczuk et al. (2016) e Rop et al. (2012), os teores médios de compostos fenólicos totais encontrados $\left(0,97\right.$ e $0,51 \mathrm{~g}$ EAG $100 \mathrm{~g}^{-1}$ de amostra fresca, respectivamente) foram inferiores para flores de amor-perfeito.

A diversidade de grupos que compõem os compostos fenólicos (BOROSKI et al., 2015) resulta, também, em diversidade de resultados de teores encontrados. Os diferentes resultados encontrados neste estudo em relação aos demais autores citados, justifica-se pela existência de variações na expressão dos compostos fenólicos, que podem sofrer interferências por diversos fatores bióticos e abióticos, como tipo de manejo da cultura, solo, clima, temperatura, pH, luz, espécies e variedades de espécies, dentre outros (FERNANDES et al., 2016; ZHAO e TAO, 2015).

Vieira (2013) encontrou teores de flavonoides totais semelhantes para flores de amorperfeito com 281,4 mg. $100 \mathrm{~g}^{-1}$ de amostra fresca de flor, mas teores inferiores para capuchinhavermelha, capuchinha-laranja e couve-flor tradicional, com médias de 50,8; 48,45 e 0,55 mg.100 g de amostra fresca de flor, respectivamente. Em estudos de Skowyra et al. (2014) e Vukics et al. (2008) teores inferiores de flavonoides totais foram encontrados em flores de amor-perfeito, com valores de 198,6 e $121 \mathrm{mg} .100 \mathrm{~g}^{-1}$ amostra seca de flor, respectivamente.

Em estudos de Espinoza et al. (2016), o teor de antocianinas totais encontrado para capuchinha-laranja também foi superior, $\left(80,3 \mathrm{mg} \cdot 100 \mathrm{~g}^{-1}\right.$ de amostra fresca) aos relatados neste estudo.

De forma geral, os teores de carotenoides, compostos fenólicos, flavonoides e antocianinas são encontrados em maiores concentrações em flores que apresentam colorações mais intensas, como é o caso das flores de amor-perfeito e capuchinha-laranja, avaliadas neste estudo. Contudo, as flores de couve-flor verde, mesmo que em baixas quantidades, apresentaram carotenoides e antocianinas em sua contituição. A presença de clorofilas nas flores da couve-flor verde, que podem ter mascararado a tonalidade dos pigmentos acessórios (TAIZ e ZEIGER, 2013).

Em outras flores comestíveis como as flores de maracujá, cravo amarelo e rosa vermelha também foram detectados compostos bioativos e os maiores teores de antocianinas foram

Persp. online: biol. \& saúde, Campos dos Goytacazes, 29 (9), 11-20, 2019

seer.perspectivasonline.com.br 
encontrados nas flores de rosa vermelha e de maracujá (405,7 e 378,5 mg cyn-3-glu.100 g-1, respectivamente), conforme relatado por Costa et al. (2014). Em flores de dálias púrpura e amarela, Lara-Cortés et al. (2014) detectaram a presença de compostos fenólicos ( 127,5 e 102,1 mg EAG.g 1 , respectivamente) e de antocianinas $\left(257,5 \mathrm{mg}\right.$ pelargonidina.100 $\left.\mathrm{g}^{-1}\right)$ para as flores de cor púrpura.

Cabe ressaltar que todas as flores avaliadas apresentaram carotenoides, flavonoides e antocianinas (que integram o grupo dos compostos fenólicos) em sua constituição. As diferentes concentrações dos grupos de compostos bioativos encontrados neste estudo, tanto em relação as espécies e variedades das flores avaliadas, como entre os resultados dos autores citados, confirmam a variação da concentração desses fitoquímicos, e vislumbra a possibilidade de controle dessas variações, conforme interesse, através de manejos agronômicos adequados para cada espécies e variedade. Assim, de uma maneira geral, as flores comestíveis concentram compostos bioativos, importantes antioxidantes naturais, e consequentemente, a ingestão frequente dessas flores resultaria em maior combate aos radicais livres e em melhorias na manutenção da saúde.

\section{CONCLUSÕES}

Todas as espécies e variedades de flores comestíveis avaliadas neste estudo apresentaram o mesmo perfil de compostos bioativos. As de ipê-amarelo destacam-se pelo conteúdo de carotenoides totais em relação às demais flores avaliadas. As de amor-perfeito e de capuchinhalaranja apresentaram os maiores teores de compostos fenólicos, flavonoides e antocianinas, enquanto que as de ora-pro-nobis e couve flor verde, foram as que apresentaram os menores conteúdos dos compostos bioativos avaliados neste estudo.

\section{REFERÊNCIAS}

BORELlA, J.; MARTINAZZO, E.G.; AUMONDE, T.Z., AMARANTE, L.; MORAES, D.M.; VILLELA, F.A. Respostas na germinação e no crescimento inicial de rabanete sob ação de extrato aquoso de Piper mikanianum (Kunth) Steudel. Acta Botanica Brasílica. v.26, n.2, p.415-420, 2012.

BOROSKI, M.; VISENTAINER, J.V.; COTTICA, S.M.; MORAIS, D.R.; Antioxidantes Princípios e Métodos Analíticos, $1^{\mathrm{a}}$ ed. Curitiba, Appris, 2015.

BOTREL, N.; MADEIRA, N.R.; RIBEIRO, R.L.V. Flor comestível, Tropaeolum majus L., uma fonte de carotenoide. Cadernos de Agroecologia, v.10, n.3, p.1-6, 2015.

BRASIL. MINISTÉRIO DA SAÚDE. Guia alimentar para a população brasileira. $2^{\mathrm{a}}$ ed. Brasília: Ministério da Saúde, 2014. 156 p.

CHITARRA, M.I.F.; CHITARRA, A.B. Pós-colheita de frutas e hortaliças: fisiologia e manuseio. $2^{a}$ ed. Lavras: UFLA, 2005. 785 p.

COSTA, L.C.; RIBEIRO, W.S.; BARBOSA, J.A. Compostos bioativos e alegações de potencial antioxidante de maracujá, cravo amarelo, rosa e capuchinha. Revista Brasileira de Produtos Agroindustriais, v.16, n.3, p.279-289, 2014.

COSTA, N.M.B.; ROSA, C.O.B. Alimentos funcionais: componentes bioativos e efeitos fisiológicos. Rio de Janeiro: Rubia. 2010, 536p.

ESPINOZA, C.S.; CHOQUE, S.; CORILLA, G.; QUISPE, M.S. Extracción de antocianinas de flores de mastuerzo (Tropaeolum majus L.) y secado por atomización. Agronomía Colombiana, v.34, p.641-644, 2016.

Persp. online: biol. \& saúde, Campos dos Goytacazes, 29 (9), 11-20, 2019

seer.perspectivasonline.com.br 
FERNANDES, L.; CASAL, S.; PEREIRA, J.A.; SARAIVA, J.A.; RAMALHOSA, E. Uma perspetiva nutricional sobre flores comestíveis. Acta Portuguesa de Nutrição, v.6, p.32-37, 2016.

FERNANDES, L.; CASAL, S.; PEREIRA, J.A.; SARAIVA, J.A.; RAMALHOSA, E. Edible flowers: A review of the nutritional, antioxidant, antimicrobial properties and effects on human health. Journal of Food Composition and Analysis, v.60, n.1, p.38-50, 2017.

GRZESZCZUK, M.; STEFANIAK, A.; PACHLOWSKA, A. Biological value of various edible flower species. Scientiarum polonorum, v.15, n.2, p.109-119, 2016.

KIM, G.-C.; KIM, J.-S.; KIM, G.-M.; CHOI, S.-Y. Anti-adipogenic effects of Tropaeolum majus (nasturtium) ethanol extract on 3T3-L1 cells. Food \& Nutrition Research, v.61, p.1-8, 2017.

KINUPP, V. F.; LORENZI, H. Plantas alimentícias não convencionais (PANC) no Brasil. Guia de identificação, aspectos nutricionais e receitas ilustradas. Nova Odessa: Instituto Plantarum de Estudos de Flora. 768p. 2014.

LARA-CORTÉS, E.; MARTÍN-BELLOSO, O.; OSORIO-DÍAZ, P.; BARRERA-NECHA, L. L.; SÁNCHEZ-LÓPEZ J.A.; BAUTISTA-BAÑOS, S. Actividad antioxidante, composición nutrimental y funcional de flores comestibles de dalia. Revista Chapingo Serie Horticultura, v.20, n.1, p.101-116, 2014.

LEES, D.H.; FRANCIS, F.J. Quantitative methods for anthocyanis. 6. Flovonols and anthocyanins in cranberries. Journal of Food Science, v.36, p.1056-1060, 1971.

LLORACH, R.; MARTÍNEZ-SÁNCHEZ, A.; TÓMAS-BARBERÁN, F.A.; GIL, M.I.; FERRERES, F. Characterization of polyphenols and antioxidant properties of five lettuce varieties and escarole. Food Chemistry, Murcia v.108, p.1028-1038, 2008.

LOIZZO, M.R.; PUGLIESE, A.; BONESI, M.; TENUTA, M.C.; MENICHINI, F.; XIAO, J.; TUNDIS, R. Edible Flowers: A rich source of phytochemicals with antioxidant and hypoglycemic properties. Journal of Agricultural and Food Chemistry, v.64, p.2467-2474, 2016.

MAY, A.; TIVELLI, S.W.; VARGAS, P.F.; SAMRA, A G.; SACCONI, L.V.; PINHEIRO, M. Q. A cultura da couve-flor. Campinas: Instituto Agronômico. Série Tecnologia APTA, Boletim Técnico IAC, 200. 36p. 2007.

MOUSAVI, S.H.; NAGHIZADE, B.; POURGONABADI, S.; GHORBANI, A. Protective effect of Viola Tricolor and Viola odorata extracts on serum/glucose deprivation-induced neurotoxicity: role of reactive oxygen species. Journal of Phytomedicine, v.6, n.4, p.434-441, 2016.

NEVES, L.C; ALENCAR, S.M.; CARPES, S.T. Determination of antioxidant activity and content of phenolic compounds and flavonoids Jounal Food Technology.VII BMCFB, 2009. Dispinível em http://www.scielo.br/scielo.php?script=sci_nlinks\&pid=S0102-

0536201400040048600014\&lng=en. Acesso em 11/12/2018

OMS. Healthy Diet. Fact Sheet, n.394, p.1-6, 2015.

PIRES, T.C.S.P.; DIAS, M I.; BARROS, L.; CALHELHA, R.C.; ALVES, M.J.; OLIVEIRA, M.B.P.P.; SANTOS-BUELGA, C.; FERREIRA, I.C.F.R. Edible flowers as sources of phenolic compounds with bioactive potential. Food Research International, v.105, p.580-588, 2018.

RODRIGUEZ-AMAYA, D.B.; KIMURA, M. Harvest plus handbook for carotenoid analysis. Washington DC e Cali: International Food Policy Research Institute (IFPRI) e International Center for Tropical Agriculture (CIAT), 2004. 58 p.

ROP, O.; MLCEK, J.; JURIKOVA, T.; NEUGEBAUEROVA, J.; VABKOVA, J. Edible flowers-A

Persp. online: biol. \& saúde, Campos dos Goytacazes, 29 (9), 11-20, 2019

seer.perspectivasonline.com.br 
new promising source of mineral elements in human nutrition. Molecules, v.17, p.6672-6683, 2012. SINGLETON, V.L.; ORTHOFER, R.; LAMUELA-RAVENTOS, R.M. Analysis of total phenols and other oxidation substrates and antioxidants by means of Folin-Ciocalteau reagent. Methods of Enzymology, v.299, p.152-178, 1999.

SILVA, .C.B.; SCHUQUEL, L.C.S.; SILVA, C.O.; PASCOAL, G.B. Nutritional and physicochemical quality in fresh and fresh-cut carrot (Daucus carota 1.). Demetra, v. 11, n. 2, p.355-367, 2016.

SKOWYRA, M.; CALVO, M.I.; GALLEGO, M.G.; AZMAN, N.A.M.; ALMAJANO, M.P. Characterization of phytochemicals in petals of different colours from Viola $\times$ wittrockiana Gams. and their correlation with antioxidant activity. Journal of Agricultural Science, v.6, n.9, p.93-105, 2014.

TAIZ, L.; ZEIGER, E. Fisiologia vegetal. 5ª ed. Porto Alegre: Artmed, 2013. 954 p.

VIEIRA, P.M. Avaliação da composição química, dos compostos bioativos e da atividade antioxidante em seis espécies de flores comestíveis. Tese (Doutorado). Faculdade de Ciências Farmacêuticas de Araraquara - UNESP, Araraquara, São Paulo, 2013.102p.

VUKICS, V.; KERY, A.; GUTTMAN, A. Analysis of polar antioxidants in Heartsease (Viola tricolor L.) and Garden pansy (Viola $\times$ wittrockiana Gams.). Journal of Chromatographic Science, v.46, n.9, p.823-827, 2008.

ZHAO, D.; TAO, J. Recent advances on the development and regulation of flower color in ornamental plants. Frontiers in Plant Science, v.6, n.4, p.1-13, 2015. 